\title{
A focus on the association of Apoll with kidney disease in children
}

\section{Pepe M. Ekulu, Agathe B. Nkoy, Oyindamola C. Adebayo, Orly K. Kazadi, Michel N. Aloni, Fanny O. Arcolino, Rene M. Ngiyulu, e}

\section{Pediatric Nephrology}

Journal of the International Pediatric Nephrology Association

ISSN 0931-041X

Pediatr Nephrol

DOI 10.1007/s00467-020-04553-z 
Your article is protected by copyright and all rights are held exclusively by IPNA. This eoffprint is for personal use only and shall not be self-archived in electronic repositories. If you wish to self-archive your article, please use the accepted manuscript version for posting on your own website. You may further deposit the accepted manuscript version in any repository, provided it is only made publicly available 12 months after official publication or later and provided acknowledgement is given to the original source of publication and a link is inserted to the published article on Springer's website. The link must be accompanied by the following text: "The final publication is available at link.springer.com". 


\title{
A focus on the association of Apol1 with kidney disease in children
}

\section{Pepe M. Ekulu ${ }^{1,2} \cdot$ Agathe B. Nkoy $^{2} \cdot$ Oyindamola C. Adebayo ${ }^{1} \cdot$ Orly K. Kazadi $^{2} \cdot$ Michel N. Aloni $^{2} \cdot$ Fanny O. Arcolino $^{1}$. Rene M. Ngiyulu ${ }^{2}$. Jean-Lambert E. Gini ${ }^{2}$. François B. Lepira ${ }^{3} \cdot$ Lamberthus P. Van den Heuvel $^{1,4}$ • Elena N. Levtchenko ${ }^{5}$}

Received: 24 October 2019 / Revised: 19 March 2020 / Accepted: 24 March 2020

(C) IPNA 2020

\begin{abstract}
Individuals of African origin have an increased risk of developing various progressive chronic kidney diseases (CKD). This risk has been attributed to genetic variants (G1, G2) in apolipoprotein-L1 (APOL1) gene. In the pediatric population, especially in children affected by sickle cell disease (SCD), by human immunodeficiency virus (HIV), or with various glomerular diseases, $A P O L 1$ risk variants have been associated with the development of hypertension, albuminuria, and more rapid decline of kidney function. The present review focuses on existing $A P O L 1$-related epidemiological data in children with CKD. It also includes data from studies addressing racial disparities in CKD, the APOL1-related innate immunity, and the relationship between APOL1 and $\mathrm{CKD}$ and pathogenic pathways mediating $A P O L 1$-related kidney injury.
\end{abstract}

Keywords APOL1 $\cdot$ Chronic kidney disease $\cdot$ Children · Genetics $\cdot$ Sickle cell disease $\cdot$ HIV-associated nephropathy

\section{Introduction}

\section{Basis for racial disparities in CKD}

Many regions around the world, particularly low- and middleincome countries (LMICs), are experiencing an increased prevalence of chronic non-communicable diseases, including chronic kidney disease [1]. In the USA, since 1984, the Secretary of Health's Task Force Report on "Black and Minority Health" has highlighted a dramatic health disparity

Pepe M. Ekulu

drmfutu@yahoo.fr

1 Department of Development and Regeneration, KU Leuven, Leuven, Belgium

2 Division of Nephrology, Department of Pediatrics, Faculty of Medicine, University Hospital of Kinshasa, University of Kinshasa, Kinshasa, Democratic Republic of Congo

3 Division of Nephrology, Department of Internal Medicine, Faculty of Medicine, University Hospital of Kinshasa, University of Kinshasa, Kinshasa, Democratic Republic of Congo

4 Department of Pediatric Nephrology, Radboud University Medical Centre, Nijmegen, Netherlands

5 Department of Pediatric Nephrology \& Department of Development and Regeneration, University Hospital Leuven, KU Leuven, Leuven, Belgium in blacks, Hispanics, Asian/Pacific Islanders, and Native Americans [2]. This disparity is more pronounced with regard to kidney diseases. Compared with Americans of European ancestry, African Americans have an approximately fourfold greater lifetime risk of kidney failure and, on average, require initiation of kidney replacement therapy at a younger age [3].

To explain this disparity, many theoretical models have been proposed showing the interactions and impact of socioeconomic status (SES) (education, employment, and income) on social determinants of health (neighborhood and environment, psychosocial factors, and health care access) [4]. Among self-identified African-Americans, low income $(<\$ 8000 /$ year) was strongly associated with prevalent kidney dysfunction defined by estimated glomerular filtration rate (eGFR) $<60 \mathrm{ml} / \mathrm{min} / 1.73 \mathrm{~m}^{2}$ [5]. It has been postulated that a lower SES leads to a lack of affordable healthy foods and poor access to health care, resulting in late diagnosis and treatment of diseases such as diabetes mellitus (DM) and hypertension (HTN), two major causes of chronic kidney diseases (CKD) [6, 7]. Regarding children, it is now generally accepted that there are specific risk factors for the development and progression of CKD in African American children [4]. Some are biological, such as premature birth or low birth weight or the presence of genetic predisposition (especially the presence of the high-risk apolipoprotein L1 (APOL1) genotype), and others are social, such as the lack of access to timely health care or adequate treatment $[4,5]$. 
The present review focuses on $A P O L 1$ as a genetic risk factor of CKD with particular attention on existing epidemiological data in children. It also includes data from studies addressing the APOL1-related innate immunity, and the relationship of $A P O L 1$ and CKD and pathogenic pathways mediating $A P O L 1$-related kidney injury.

\section{Genetic predisposition to CKD among those of African descent}

Since the report of dramatic health disparity in American populations between the1980s and 2008, genetic risk of kidney disease in association with complex kidney phenotypes was largely underestimated [8]. Interestingly, it has been observed that individuals of African origin carry an excessive burden of CKD and kidney failure compared with individuals of other ancestries, even after adjusting for socioeconomic status, lifestyle, and clinical factors including diet and hypertension, suggesting genetic factors as a key contributor to this racial disparity [9]. These observations led to the analysis of ancestry informative population variation data to help explain this ancestry-driven health disparity [10].

In 2008, two research groups [11, 12] provided the first indication that genetic variants on chromosome 22 contribute to the pathogenesis of CKD [13]. They demonstrated highly significant associations of markers on human chromosome $22 \mathrm{q}$ with idiopathic focal segmental glomerulosclerosis (FSGS), HIV-associated nephropathy (HIVAN), and nondiabetic kidney failure in African Americans [3]. Using mapping by admixture linkage disequilibrium (MALD) to quantify the ancestry percentage of each genetic locus, both groups identified a locus on chromosome 22q12 associated with nondiabetic kidney disease in those of African descent $[13,14]$. This 1.2-Mb locus contained 35 genes, including non-muscle myosin heavy chain 9 (MYH9) [13]. In the kidney, MYH9 encodes an essential protein required for the proper functioning of podocyte cytoskeleton, being involved in cell motility and cell-cell adhesion [11]. Previously associated with glomerulosclerosis in patients with autosomal-dominant MATINS syndrome (macrothrombocytopenia, granulocyte inclusions with or without nephritis, and sensorineural hearing loss, MIM no. 155100) and given its podocyte expression, MYH9 was rapidly identified as a particularly strong genetic candidate to explain the association of this locus with CKD $[13,14]$. However, despite the initial enthusiasm, no plausible causal variants with a clear predicted functional effect have been identified within this gene $[3,10]$. However, the extended linkage disequilibrium and haplotype length in the $M Y H 9$ genetic locus suggested the possibility of effective causal variants in the neighboring genes [9].

In 2010 , two research groups $[15,16]$ re-examined the chromosome 22 locus for causal variants outside of MYH9, using data from the International HapMap and 1000 Genomes Projects, consisting of DNA sequences data of hundreds of individuals, including Africans and Europeans. Data from these studies revealed new information on available coding variants within the APOL1 gene that were in strong linkage disequilibrium with $M Y H 9$ risk haplotypes and exhibited even stronger associations with FSGS, hypertension-attributed kidney failure, and nondiabetic kidney failure [9]. APOL1 is a 14.5-kb gene with seven exons, located less than 14-kb upstream of MYH9, and encoding apolipoprotein L1 (APOL1), a 398 amino acid protein. Two main coding variants in APOL1 associated with kidney disease have been identified in the last exon (exon 7): the G1 allele, with two SNPs [rs73885319 $(\mathrm{A} \rightarrow \mathrm{G})$ and $\mathrm{rs} 60910145(\mathrm{C} \rightarrow \mathrm{T})]$ which result in 2 amino acid substitutions: serine for glycine at position 342 [p.Ser342Gly] and isoleucine for methionine at position 384 [p.Ile384Met], respectively. These two nonsynonymous coding variants are in almost complete linkage disequilibrium since they are always present together within an allele; the $\mathrm{G} 2$ allele, located at 12 base pairs away from G1 (rs60910145) site, is a 6 base pair deletion (rs71785313), resulting in a two-amino acid deletion at the C-terminus, asparagine and tyrosine amino acid at positions 388 and 389 (p.N388_Y389del) $[15,16]$. The two coding variants in APOL1 are in complete negative linkage disequilibrium since they never occur on the same allele. Based on odds ratios (OR) and $p$ values, APOL1 risk variants were more strongly associated with kidney failure than potential $M Y H 9$ risk variants $[15,17]$. African Americans homozygous or compound heterozygous for $A P O L 1$ risk alleles had increased risk of HIVAN $(\mathrm{OR}=29)$, FSGS $(\mathrm{OR}=17)$, and CKD stage 5 $(\mathrm{OR}=7)$ [10]. Given the high frequency of these kidney risk variants (KRVs) in African Americans and Yoruba (Nigeria) and their absence in individuals of European ancestry and Asians, it has been postulated that positive selection increased the frequency of these APOL1 KRVs in Africa [16].

\section{How does APOL1 confer an innate immunity?}

Prior to its known role in kidney disease, $A P O L 1$ was initially known as a protector against certain trypanosomes in humans and higher primates [10]. In addition, harboring of APOL1 KRVs enhanced protective ability against human African trypanosomiasis (HAT), the deadliest form of African sleeping sickness, which was endemic in Africa many years ago and still affects millions of Africans today [10, 15].

$A P O L 1$ is part of a six-member family of $A P O L$ genes (APOL1, APOL2, APOL3, APOL4, APOL5, and APOLO) located on chromosome 22 that arose through gene duplication $[18,19]$. Although several $A P O L$ genes are widespread in the animal kingdom, $A P O L 1$ is present only in a few species in the primate lineage, namely humans, gorillas, and baboons 
[18]. APOL1, a protein product of APOL1 gene, is also expressed widely in tissues, particularly in the lung, placenta, pancreas, liver, and kidney. In the kidney, APOL1 was found to be expressed in extraglomerular vascular endothelial cells, podocytes, and proximal tubular cells $[13,19]$. APOL1 circulates in blood at high levels as part of the high-density lipoprotein (HDL) complex that also contains apolipoprotein A1 (APOA1) and haptoglobin-related protein (HPR). This complex, named trypanosome lytic factor (TLF), confers innate protection against subspecies of Trypanosoma brucei [18, 19]. Two different serum complexes have been identified as trypanosome lytic factors. TLF1 is the densest fraction of HDL particles (known as fraction 3 or HDL3) and TLF2 is a distinct complex that is poor in lipids but that contains natural IgMs as a major component. Both complexes also contain the primate-specific proteins HPR and APOL1. HPR is involved in targeting TLF1 to the parasite and APOL1 is the trypanolytic toxin of both complexes [19, 20].

As illustrated in Fig. 2, APOL1 has five functional and structural domains: a secretory domain, pore-forming domain, B cell lymphoma 2 homology domain 3, membraneaddressing domain, leucine zipper domain, and serum resistance-associated (SRA) interacting domain, listed from the N-terminal to C-terminal respectively [10]. The secretory domain allows expression of serum protein. HPR enables internalization of TLF1 into the parasite, as the TLF1-bound HPR-hemoglobin complex is an alternative ligand for the T. brucei surface receptor for haptoglobin-hemoglobin, which is known as TbHpHbR [20]. While TLF1 uptake occurs by receptor-mediated endocytosis, how TLF2 enters trypanosomes is still unclear. TLF2 can be internalized by trypanosomes in the absence of TbHpHbR. After TLF1 and/or TLF2 uptake, APOL1 seems to be released from the carrier complexes and delivered to the lysosome where it causes osmotic swelling. On the other hand, the kinesin TbKIFC1 allows APOL1 delivery to the mitochondrion, leading to rapid membrane depolarization and TbEndoG nuclease release, resulting in nuclear DNA fragmentation and heterochromatinization $[20,21]$. The pore-forming domain of APOL1 is responsible for trypanosome lysis, presumably following ionic-pore formation in endosomal membranes after anchoring via a contiguous membrane-addressing domain [20].

There are three main species of Trypanosoma: Trypanosoma brucei brucei infects many mammals but is unable to infect humans due to the innate protection conferred by TLFs; Trypanosoma brucei rhodesiense (T.b. rhodesiense) which occurs in East and Central Africa, causing acute HAT; Trypanosoma brucei gambiense (T.b. gambiense), widely distributed in West and Central Africa, causes chronic HAT, which is the most common [22]. Both T.b. rhodesiense and T.b. gambiense have evolved a mechanism to evade TLF lysis. T.b. rhodesiense evades lysis by expressing SRA proteins that bind to the $\mathrm{C}$-terminus domain of APOL1, in the process neutralizing its lytic activity leading to infection and sleeping sickness $[10,20]$. In turn, T.b. gambiense resists TLFs via a multifactorial defense mechanism. A hydrophobic b-sheet of the T. b. gambiense-specific glycoprotein (TgsGP) prevents APOL1 toxicity and induces stiffening of membranes upon interaction with lipids. Two additional features contribute to resistance to TLFs: reduction of sensitivity to APOL1 requiring cysteine protease activity, and $\mathrm{TbHpHbR}$ inactivation due to an L210S substitution [20]. The APOL1 risk variants are located near the C-terminus in the SRA domain (Fig. 2), the binding site for SRA protein, a trypanosomal virulence factor $[19,23]$. It has been demonstrated that both $A P O L 1$ risk variants $\mathrm{G} 1$ and $\mathrm{G} 2$ restore the lytic activity of human serum, and this provides the selective advantage to carriers against sleeping sickness caused by only T.b. rhodesiense but not gambiense [14, 15]. By restoring the trypanolytic activity of APOL1, these variants confer an adaptive advantage in the endemic regions of Africa, explaining the distribution of G1 and $\mathrm{G} 2$ risk variants in Africa [10,21].

The understanding of distribution of G1 and G2 variants worldwide is driven by the origins, the selection story, and spreading of these variants. It is estimated that $A P O L 1$ risk variants $\mathrm{G} 1$ and $\mathrm{G} 2$ emerged about 10 thousand years ago in the trypanosome endemic region across sub-Saharan Africa, originally in West Africa, where they have been subjected to intense positive selection $[18,19]$. Humans who carried these $A P O L 1$ risk variants had a survival advantage against potentially lethal trypanosomal disease, but at a cost of increased susceptibility to glomerular injury. This protective advantage led to rapid spread of these alleles in Africa, and was then brought to American continents from along the Atlantic coast of Africa, which was the source of the Atlantic slave trade $[15,18,19]$.

\section{Modifying factors: is carrying two APOL 1 risk variants sufficient for the development of kidney disease?}

APOL1 risk variants confer an increased risk of non-diabetic CKD in African Americans [24]. However, it has been observed that only a minority of individuals who are homozygous or compound heterozygous for $A P O L 1$ risk alleles (less than $15 \%$ ) are predicted to develop kidney dysfunction and failure, reflecting the incomplete penetrance of $A P O L 1$-associated disease $[19,25]$. This suggests that the presence of two APOL1 risk variants is necessary, but not sufficient for the development of kidney diseases. Environmental and genetic interactions may contribute as modifier factors or a "second hit" to induce kidney disease [8, 25].

Various environmental factors have been reported, including HIV infection and non-HIV viral infections (such as John Cunningham (JC) polyomavirus), and factors of immune response and inflammation [24]. HIV is the strongest 
environmental risk factor for $A P O L 1$ kidney disease. In an individual with HIV infection, the high-risk genotype (HRG) increases the risk of developing HIV-associated nephropathy (HIVAN) by 29-89-fold [26, 27]. The JC polyoma virus has been proposed to mitigate the genetic risk posed by APOL1 variants $[10,28]$. Infection/colonization of the kidneys and urinary tract with JC polyoma virus has a paradoxical protective effect on risk for CKD in the presence of $A P O L 1$ risk variants. The JC virus in the kidney was postulated to either protect against other nephropathic viruses or alter cellular function as protection against other sources of glomerular injury [10]. Moreover, other studies have extended this protective association with JC polyoma virus to non-APOL1associated etiologies of nephropathy [24, 29].

Additional environmental factors, including some markers of inflammation, have been reported. In a case series of interferon (IFN)-induced collapsing nephropathy, all genotyped patients had the APOL1 HRG [19, 30]. In vitro studies showed that multiple types of IFN could stimulate APOL1 expression by up to 200-fold [30]. Lupus, HIV, and other FSGS induced by viral infections are known to be associated with high IFN state [19, 31]. Other inflammatory factors, including toll-like receptor (TLR) agonists and tumor necrosis factor (TNF)-alpha, have been shown to induce overexpression of APOL1 in podocytes and endothelial cells leading to kidney disease [19, 30]. Furthermore, circulating soluble urokinase receptor (suPAR) has been shown to interact with APOL1 to activate $\alpha v \beta$ integrin and induce podocyte injury [24, 32].

Several groups have studied the role of potential APOL1 interacting genes in non-diabetic CKD. Some candidate genes, including podocin (NPHS2), serologically defined colon cancer antigen 8 (SDCCAG8), ectoNOX disulfide-thiol exchanger 1 (ENOX), bone morphogenetic protein 4 (BMP4), a null variant in the apolipoprotein L3 (APOL3), and glutathione s-transferase mu 1 (GSTM1) genes have been explored [24]. However, no genetic modifiers have been shown to have a major impact on APOL1 HRG penetrance [19, 24].

More recently, Langefeld et al. [33] performed a large genome-wide association study (GWAS) and meta-analysis to identify novel loci for non-diabetic CKD stage 5 in African Americans and to detect new genetic modifiers of APOL1-associated nephropathy. No significant genome-wide associations with kidney failure beyond APOL1 were detected, and no single nucleotide polymorphism (SNP) showed significant genome-wide evidence of interaction with $A P O L 1$ risk variants. Thus, it was concluded that APOL1-environment interactions may be of greater importance in triggering nephropathy in African Americans than APOL1 interactions with other SNPs.

\section{APOL1 and biological mechanisms of kidney injury}

As previously mentioned, APOL1 is expressed in various tissues and cell types. However, to date, the manifestations of kidney disease related to $A P O L 1$ risk variants have been limited to the podocytes and possibly microvascular endothelial cells [9]. Although the precise mechanisms by which APOL1 G1 and G2 variants induce injury in podocytes and other kidney cells, compared with the reference allele G0, remain unclear [24], various pathways of kidney cell damage by APOL1 are being proposed and much of the data come from studies in cultured cells [9, 34] (Fig. 1). The first proposed mechanism consists of the overexpression of APOL1 in podocytes associated with cellular injury and glomerular damage. Studies have reported that activation of TLR3 and cytokines such as IFN $\Upsilon$ and TNF upregulates APOL1 expression, regardless of the genotype, resulting in cell injury [30,34, 35]. However, it has been demonstrated that overexpression of the APOL1 risk variants is more injurious to cells than overexpression of the wild-type APOL1 protein [30]. In addition, Poly(I:C), which is a double-stranded RNA TLR3 agonist, increased APOL1 expression by upregulating IFNs. As in the second mechanism, increased expression of APOL1 risk variants has been shown to induce inflammasome activation. Once activated, inflammasome processes pro-IL- $1 \mathrm{~b}$ and proIL-18 into active forms and induces cell death pathways [9, 30]. The third mechanism postulates that overexpression of G1 and G2 in cultured human podocyte activates protein kinase R (PKR), leading to reduced cell protein synthesis resulting in cell stress or death [36]. Furthermore, the activation of PKR also activates inflammasomes and results in activation of caspase- 1 and generation of active IL- $1 b[30,36]$. In addition, using cell models, increased expression of risk variants has been shown to induce a loss of cellular potassium $\left(\mathrm{K}^{+}\right)$with subsequent induction of stress-activated protein kinase (SAPK) pathways [24, 38]. It has been suggested that APOL1 acts as $\mathrm{K}^{+}$-permeable cation-selective pore in the plasma membrane, and the risk variants G1 and G2 are associated with greater flux and cellular $\mathrm{K}^{+}$depletion $[9,24]$. Another mechanism postulates that G1 and G2 overexpression impairs mitochondrial function. Indeed, Ma et al. [37] observed that $A P O L 1 \mathrm{G} 0$ overexpression increased oxygen consumption rate and preserved respiratory capacity, whereas G1 and G2 overexpression decreased oxygen consumption rate and reduced respiratory capacity. This mitochondrial dysfunction could lead to plasma membrane $\mathrm{Na}^{+} / \mathrm{K}^{+}$ATPase inhibition, resulting in intracellular potassium depletion. Thus, the authors suggested that mitochondrial dysfunction is present prior to intracellular $\mathrm{K}^{+}$depletion in cells overexpressing $\mathrm{G} 1$ and $\mathrm{G} 2$ alleles. In a sixth proposed mechanism, using cell and animal models, investigators demonstrated increased lysosomal permeability owing to expression of $A P O L 1$ variants 


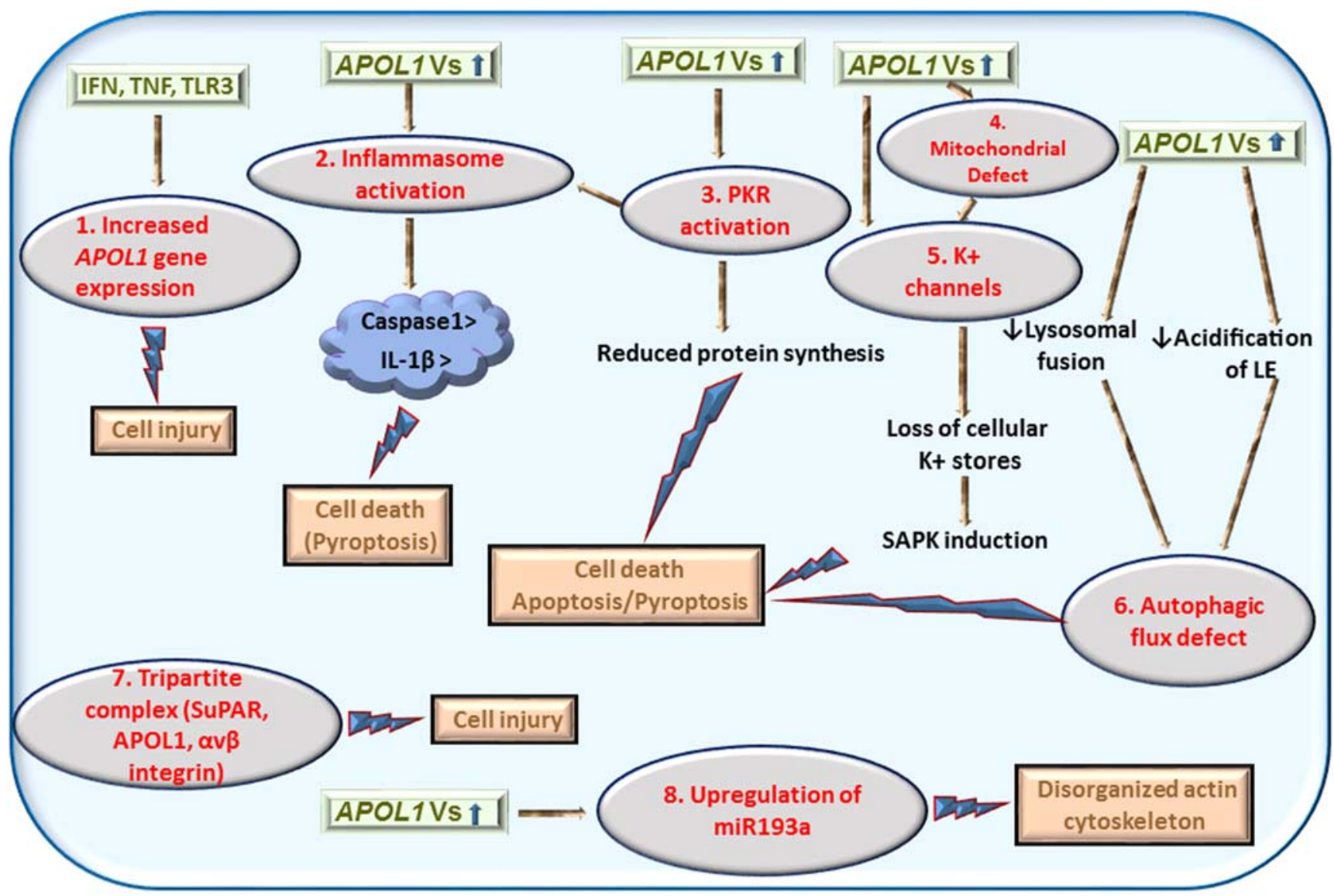

Fig. 1 Postulated pathways of cell injury in APOL1-associated kidney disease. Eight mechanisms proposed to date to explain how APOL1 risk variants induce kidney cell damage. From the first pathway to the eighth, these are the following: overexpression of APOL1 risk variants [30, 35], inflammasome activation [30], PKR activation [36], mitochondrial defect

[39]. Furthermore, they reported that expression of APOL1 variants disrupts endolysosomal trafficking, leading to autophagic flux defects followed by autophagic cell death [34, 39, 40]. In a recent study, Hayek et al. [32] identified highaffinity interactions between suPAR, APOL1, and $\alpha \mathrm{v} \beta 3$ integrin, whereby APOL1 protein variants G1 and G2 exhibited higher affinity for suPAR-activated $\alpha \mathrm{v} \beta 3$ integrin than for APOL1 G0. APOL1 G1 or G2 augmented $\alpha \mathrm{v} \beta 3$ integrin activation and caused proteinuria in mice in a suPARdependent manner. They concluded that the synergy of circulating factor suPAR and APOL1 G1 or G2 on $\alpha \mathrm{v} \beta 3$ integrin activation is a mechanism for CKD [24, 32]. More recently, Kuma et al., using a transduced human podocyte cell model, found that overt expression of APOL1 G0 in podocytes downregulated the expression of miR193a. The expression of APOL1 G1 and G2 was associated with upregulation of miR193a resulting in a disorganized actin cytoskeleton [41].

As noticed above, all these studies used cell and animal models to explain the mechanism whereby APOL1 risk variant expression induces damage in kidney cells, but to what extent these mechanisms are involved in humans is still
[37], $\mathrm{K}^{+} / \mathrm{Na}^{+}$channel activation [38], autophagic flux defect [39, 40], cytotoxicity due to the tripartite complex [32], and upregulation of miR193a resulting in altered actin cytoskeleton [41]; APOL1 Vs $\uparrow:$ increased expression of APOL1 risk variants

unknown. Further confirmatory studies in models much closer to human conditions are needed in order to promote therapeutic approaches to thwart these kidney cell damage pathways.

\section{$A P O L 1$ and susceptibility to CKD}

The APOL1 risk alleles have been observed only in individuals of African descent. While the presence of at least one allele (G1 or G2) is sufficient to confer protection against Trypanosoma rhodesiense (innate immunity occurring in dominant fashion), the transmission of kidney disease risk is consistent with recessive inheritance. As shown in Fig. 2, for the development of CKD, the presence of two alleles in homozygous (G1/G1 or $\mathrm{G} 2 / \mathrm{G} 2)$ or compound heterozygous $(\mathrm{G} 1 / \mathrm{G} 2)$ state is necessary and is defined as a HRG $[7,19]$. Carrying one risk allele causes at most only a slight increase in kidney disease risk, whereas HRG increases this risk dramatically [19]. In this way, $A P O L 1$ is similar to sickle cell trait: while patients who carry heterozygous and homozygous mutations in the hemoglobin gene are protected against malaria, 


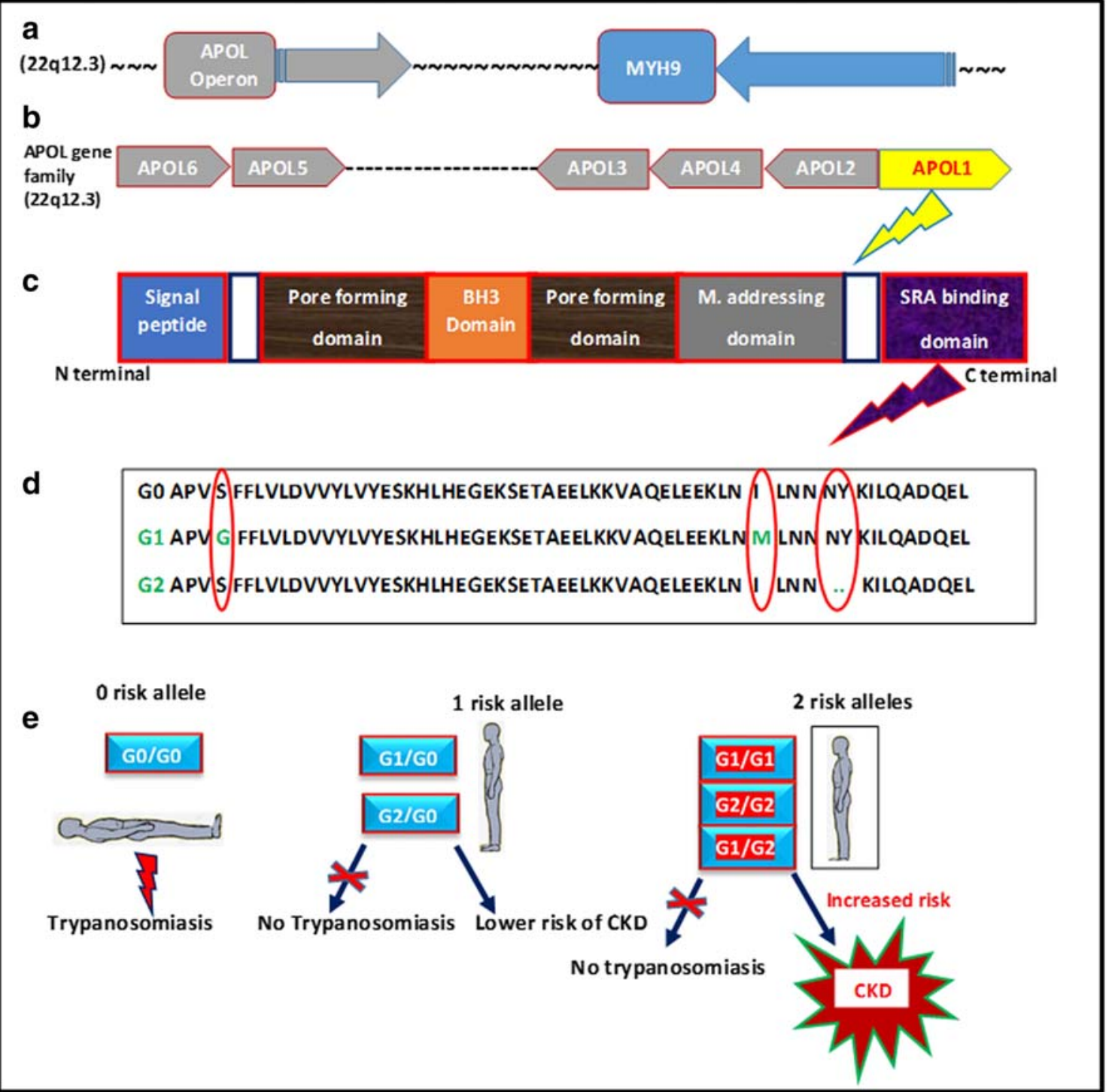

Fig. 2 Sequence variants in apolipoprotein L1 confer an innate immunity to trypanosomal infection and increase susceptibility to CKD in African populations. a Schematic illustration of position of $A P O L$ operon on human chromosome 22q12.3; the MYH9 gene is also located in this region. The two genes are separated by 14,000 nucleotides. b Schematic diagram displaying the genomic organization of members of $A P O L$ gene family with $A P O L 1, A P O L 2, A P O L 3$, and APOL4 gene cluster resulting from tandem gene duplication, whereas $A P O L 5$ and APOL6 are more distantly related. APOL1 is in the opposite orientation to the other three genes. c The structure of APOL1 (398 amino acid proteins) with multiple protein domains. d G1 (S342G and I384M) and

only those with the homozygous mutation develop sickle cell anemia [7, 19]. Nevertheless, a mild dominant influence (OR 1.2 for one risk allele compared with 7.3 for two risk alleles) has been observed in a larger cohort of hypertensionassociated CKD. This raised the hypothesis of sporadic mutations which might occur in patients carrying one risk variant or additional rare variants in $A P O L 1, M Y H 9$, or other neighboring genes $[10,14]$.
G2 (deletion of N388 and Y389) sequence variants are located at the Cterminus of APOL1. The close proximity of the G1 and G2 alleles results in a low likelihood of recombination between the two alleles. G1 and G2 are reciprocally exclusive and never appear together on the same chromosome. e Illustration of the different clinical consequences in APOL1 carriers: individuals with two APOL1 wild-type (WT) alleles (G0) are prone to Trypanosoma brucei rhodesiense infection. The presence of one $A P O L 1$ risk variant, $\mathrm{G} 1$ or $\mathrm{G} 2$, expands trypanosomal resistance including $T$. $b$. rhodesiense. The presence of two $A P O L 1$ risk variants continues to protect against $T$. $b$. rhodesiense, but increases the risk for APOL1-associated CKD

Initially, studies which investigated the relationship between APOL1 and kidney disease were mostly case-control studies of extreme phenotypes, especially CKD stage 5 and FSGS $[8,15]$. Population-based longitudinal studies have been conducted subsequently and showed an association with progressive disease over the years leading to kidney failure [7, 8]. As described in Table 1, various studies have reported the odds of different kidney diseases in patients of African 
Table 1 Odds of various kidney diseases in individuals of African ancestry carrying $A P O L 1 \mathrm{HRG}$

\begin{tabular}{lllll}
\hline Population & Disease & OR (95\%CI) & Year & Author \\
\hline African Americans & Hypertensive ESRD & $7.3(5.60-9.50)$ & 2010 & Genovese [15] \\
& FSGS & $10.5(6.0-18.4)$ & & \\
African Americans & Non-diabetic ESRD & $4.86(2.35-10.06)$ & 2010 & Tzur [16] \\
African Americans & HIVAN & $29.2(13.10-68.50)$ & 2011 & Kopp [26] \\
& FSGS & $16.9(11.00-26.50)$ & & \\
South African blacks & HIVAN & $89.10(17.68-911.72)$ & 2015 & Kasembeli [27] \\
African Americans & SRNS & $4.17(2.23-7.64)$ & 2018 & Adeyemo [42] \\
\hline
\end{tabular}

$E S R D$, end-stage renal disease; FSGS, focal segmental glomerulosclerosis; HIVAN, human immunodeficiency virus associated nephropathy; $S R N S$, steroid-resistant nephrotic syndrome ancestry carrying APOL1 HRG $[15,16,26,27,42]$. An association between the HRG and increased risk of sickle cell nephropathy and increased risk of severe lupus nephritis has also been reported [43]. Furthermore, the presence of APOL1 HRG has been found to accelerate progression of CKD to kidney failure in patients with FSGS and hypertensive nephrosclerosis despite immunosuppressive therapy and blood pressure control, respectively [7, 44]. Regarding diabetic nephropathy (DN), the relationship with $A P O L 1$ remains particularly poorly defined. The APOL1 HRG appears to be associated with progression of DN but not with the incidence of DN [45].

\section{APOL1 and the susceptibility to kidney disease in children and young adults}

As shown in several aforementioned studies, most existing data on APOL1 and susceptibility to CKD are focused on adults. There has been a paucity of studies examining pediatric APOL1-associated CKD. Yet, there is a strong need for more prospective studies to determine the role of APOL1 in the pediatric population. In response to this need, the collaboration between the Chronic Kidney Disease in Children (CKiD) Study and the Nephrotic Syndrome Study Network (NEPTUNE) allowed investigation of the APOL1 status of children with glomerular diseases [46]. Similar to adults, children with glomerular disease who carried APOL1 HRG had lower eGFR at study entry and experienced a steeper decline in kidney function. It has been demonstrated that children with APOL1 HRG have a 2-4-fold faster rate of glomerular filtration decline than children carrying a low-risk genotype [46]. Few other studies have investigated the relationship between APOL1 and CKD in children, including two prevalent diseases shown to be strongly associated with APOL1-mediated CKD: HIV infection and sickle cell disease (SCD) [8, 47].

\section{HIVAN}

The strongest association between APOL1 and CKD in adults has been found for HIV-associated nephropathy (HIVAN), with an OR of 29 in the USA [26] and 89 in South Africa [27]. In a case-control study of 451 perinatal HIV infection (PHIV) participants in the Pediatric HIV/ AIDS Cohort Study, Purswani et al. found that $27 \%$ of CKD cases in the adolescent cohort carried 2 risk alleles. Moreover, there were 3.5 -fold increased odds of CKD in those with the APOL1 HRG with unadjusted incidence of 1.2 CKD cases/100 person-years [47].

More recently, in the Democratic Republic of Congo, we assessed the association between APOL1 HRG and earlystage CKD in 813 children (401 HIV-infected and 412 from the general population) [48]. From 412 healthy children recruited in the general population, albuminuria (defined as ACR $\geq 30 \mathrm{mg} / \mathrm{g}$ ) was present in $40(9.7 \%)$. We observed a weak association of HRG and albuminuria in the healthy population, which was not retained in a multivariate analysis. On the other hand, we found a strong association between APOL1 HRG and albuminuria in HIV-infected children. From 401 HIV-infected children treated with antiretroviral drugs with non-kidney toxicity following the guidelines for integrated HIV management in DRC (the DRC National AIDS Control Program), albuminuria was detected in $72(18.0 \%)$. Almost $78 \%$ of HIV-infected children who carried APOL1 HRG presented with albuminuria, compared with $14.3 \%$ of those carrying LRG (unadjusted OR 21.60, 95\%CI 7.25-76.62; $p<0.001)$. Multivariate logistic regression analysis showed that APOL1 HRG (adjusted OR 32.56, 95\% CI 9.94$106.58 ; p<0.001)$ and a high viral load (defined by a copy number $>1000 / \mathrm{ml}$ ) (adjusted OR 10.34, 95\%CI 5.29-20.23; $p<0.001)$ were the only independent risk factors associated with elevated albuminuria. Furthermore, HIV-infected children who carried the HRG had a significantly higher blood pressure, and the proportion of those with elevated blood pressure (defined as above 95 th percentile) was almost double that observed in those without HRG. 


\section{Sickle cell nephropathy}

APOL1 risk alleles may also be involved in the development of sickle cell nephropathy. Two recent studies reported the association of APOL1 HRG with albuminuria and a lower eGFR. Kormann et al. [49] assessed the role of APOL1 variants in SCD patients living in Europe. From 152 SCD young adult patients of African ancestry recruited in France, investigators showed that APOL1 HRG was associated in an agedependent manner with lower eGFR, $(p=0.008)$, proteinuria $(p=0.009)$, and albuminuria $(p<0.001)$. In a cohort of 413 SCD young adults from Cameroon, $A P O L 1$ HRG was significantly associated with albuminuria $(p=0.01)$ and borderline with eGFR $(p=0.07)$ [50].

\section{Nephrotic syndrome}

Idiopathic nephrotic syndrome (INS) is the most frequent glomerular disease of childhood. Epidemiologic studies have established that there is significant ethnic disparity in the prevalence and clinical course of steroid-sensitive nephrotic syndrome (SSNS) [42], suggesting the interaction between environmental and genetic factors as major contributors. In view of the role of APOL1 variants in a variety of CKD in populations of African ancestry, and considering the previous report on the role of the gene encoding major histocompatibility complex-class II-DQ-alpha 1 (HLA-DQA1) in children of South Asian and European ancestry with SSNS, Adeyemo et al. [42] tested the hypothesis that HLA-DQA1 and APOL1 risk variants are associated with SSNS or steroidresistant nephrotic syndrome (SRNS) in a sample of 115 African American children. They showed that HLA-DQA1 variants were significantly associated with SSNS in African American children (OR 4.8) but not SRNS. On the other hand, APOL1 risk variants were not associated with SSNS but showed significant associations with SRNS (OR 4.17).

Furthermore, recently, Watanabe et al. reviewed the specific genes and loci discovered in childhood NS, including APOL1-associated NS in black patients [51]. The authors reported that in the pediatric nephrology clinic, they found 60 $70 \%$ of African American children with NS harbor an APOL1 HRG. However, they noticed that African-origin children with NS are not routinely screened for the APOL1 HRG. The authors believe this would surely change in patients with NS if APOL1-targeted therapies are developed or modifiable factors are discovered that affect the progression of kidney disease in these children [51]. As with other varieties of pediatric CKD, there is still a paucity of studies examining pediatric APOL1mediated NS. Yet, there is a need for more studies focusing on genetic risk factors of NS to explain disparities in disease incidence and response to therapy. The results may potentially lead to the identification of new therapeutic targets for nephrotic syndrome.

\section{Cardiovascular morbidity}

Some reports have shown that almost $14 \%$ of African Americans who carried APOL1 HRG had an increased potential risk of developing CKD and possibly cardiovascular diseases [22]. Within the CKiD Study, Woroniecki et al. [52] reported increased odds of cardiovascular morbidities among African American children with FSGS and carrying APOL1 HRG. The investigators observed a higher prevalence of uncontrolled hypertension, left ventricular hypertrophy (LVH), elevated C-reactive protein levels, and obesity in children with FSGS carrying APOL1 HRG than in those bearing 0 or 1 risk allele $[4,52]$. On the other hand, in children with hypertensive disease or FSGS, a higher proportion of APOL1 risk alleles has been observed among those with a family history of kidney failure, emphasizing the important role of family history screening irrespective of genetic testing [8]. However, while the incidence of cardiovascular morbidities and kidney disease is generally higher among APOL1 HRG compared with that among LRG carriers [52], it is still not clear whether this increased cardiovascular risk occurs due to the underlying CKD or is present independently [8,52]. More studies are required to elucidate this issue.

\section{$A P O L 1$ risk variants prevalence studies: data in children}

Data on the incidence of $A P O L 1$ alleles in Africa have shown highly variable frequencies of the risk alleles. Western Africa region has been reported to be the epicenter of $A P O L 1$ variants, with the highest frequencies occurring in Ghana and Nigeria (G1, > 40\%; G2, 6-24\%); but these risk variants are nearly absent in Eastern African countries, such as Ethiopia $[18,22]$. Furthermore, a scarcity of APOL1-related genotypic data was observed in Central Africa [22]. In addition, data showed that the G1 allele is highly concentrated in Western Africa, whereas the $\mathrm{G} 2$ allele is more widely distributed across the continent [18]. High prevalence of $A P O L 1$ risk variants has also been reported in African Americans living in the USA, one of the destination countries of the Atlantic slave trade. It has been shown that the frequency of G1 and G2 alleles in African Americans is 20-22\% and 13-15\%, respectively, and approximately $10-15 \%$ have two APOL1 risk alleles (HRG) [18, 19].

Moreover, most studies that have reported prevalence of APOL1 risk alleles and examined the relationship between APOL1 and kidney disease were focused on adults. A few recent papers have reported the prevalence of $\mathrm{G} 1, \mathrm{G} 2$, and APOL1 HRG in the general pediatric population and in children with kidney disease (Tables 2 and 3). As shown in Table 2, in perinatal HIV-infected African American children, Purswani et al. reported that $13 \%$ carried APOL1 HRG and 
Table 2 Studies on prevalence of APOL1 HRG in pediatric population

\begin{tabular}{llllll}
\hline Population & Country & Author & Year & Participant $(n)$ & APOL1 HRG $(\%)$ \\
\hline Perinatal HIV infection AA children & USA & Purswani [47] & 2016 & 302 & 13 \\
Young adults of African descent with sickle cell & France & Kormann [49] & 2017 & 152 & 7 \\
HIV-infected children & DRC & Ekulu [48] & 2019 & 401 & 6 \\
General pediatric population & DRC & Ekulu [48] & 2019 & 412 & 7 \\
\hline
\end{tabular}

$H R G$, high-risk genotype; $A A$, African American; USA, United Stated of America; $H I V$, human immunodeficiency virus; $D R C$, Democratic Republic of Congo

$43 \%$ had one risk allele (G0/G1,G0/G2) [47]. Kormann et al. reported $7 \%$ of $A P O L 1 \mathrm{HRG}$ in a cohort of young adults of African descent with SCD living in France [49]. More recently, in Central Africa, we reported the prevalence of APOL1 KRVs in 813 children. Of 412 children from the general population, the frequency of the G1 and G2 alleles was $12.4 \%$ and $10.4 \%$, respectively, and $7 \%$ had APOL1 HRG. On the other hand, of the 401 HIV-positive children, there were $13.5 \%$ and 9.6\% of G1 and G2 alleles, respectively, and $5.7 \%$ had APOL1 HRG [48]. In addition, as shown in Table 3, the prevalence of APOL1 HRG (9-46\%) has been reported in pediatric populations presenting with some features of kidney disease [42, 46-49, 52].

\section{APOL1 implications in kidney transplantation in children and young adults}

Data from the CKiD study showed that African American children reached the start of kidney replacement therapy 3.2 years earlier than non-African American children [46]. Recently, Guan et al. [53] evaluated associations between race and transplant outcomes in children diagnosed with FSGS. The authors observed that graft survival was significantly shorter in black children than that in the non-black group $(p<0.005)$. African-origin children presented with 1.3 increased risk of graft failure, and 1.7 and 1.5 increased odds of acute rejection and delayed graft function, respectively. Interestingly, some retrospective studies have reported shorter kidney allograft survival from deceased donors with APOL1 HRG $[54,55]$. These studies suggest that the worse survival of kidney grafts from African American donors is due to the presence of HRG. They observed that the recipient APOL1 genotype status had no effect on the outcomes of kidney allografts, suggesting little role for circulating APOL1 protein in shorter kidney allograft survival.

Moreover, these observations raise an important ethical concern related to the implementation of routine APOL1 testing in clinical care, particularly among potential African American kidney donors. It has been suggested that determining APOL1 genotype among routine kidney donor panel tests in recent African ancestry could better predict outcomes after kidney transplantation [56]. Implications of these observations have a particular resonance in children and young adults, whose parents may wish to donate regardless of the risk related to their APOL1 status, given that living kidney donation is known to be better for the child. This issue is all the more delicate to address as the number of recipients continues to increase while the number of donors decreases [8]. While there is evidence of the strong association between APOL1 HRG and worsened allograft outcomes, the causality of APOL1 HRG has not been established yet [7]. Some authors propose that routine $A P O L 1$ variant testing should be performed in routine clinical care and recommend $\mathrm{HRG}$

Table 3 Prevalence of APOL1 HRG in children and young adults with features of kidney disease

\begin{tabular}{|c|c|c|c|c|c|}
\hline Population with kidney disease & Country & Author & Year & Participant $(n)$ & APOL1 HRG $(\%)$ \\
\hline AA children with FSGS & USA & Woroniecki [52] & 2016 & 140 & 24 \\
\hline Perinatal HIV infection AA children with CKD & USA & Purswani [47] & 2016 & 23 & 30 \\
\hline AA children with glomerular disease & USA & $\mathrm{Ng}$ DK [46] & 2017 & 104 & 46 \\
\hline Young adults of African descent with sickle cell with U-ACR $\geq 30 \mathrm{mg} / \mathrm{g}$ & France & Kormann [37] & 2017 & 111 & 9 \\
\hline AA children with SRNS & USA & Adeyemo [42] & 2018 & 50 & 40 \\
\hline AA children with SSNS & USA & Adeyemo [42] & 2018 & 65 & 17 \\
\hline HIV-infected children with $U$-ACR $\geq 30 \mathrm{mg} / \mathrm{g}$ & DRC & Ekulu $[48]$ & 2019 & 72 & 25 \\
\hline General pediatric population with $\mathrm{U}-\mathrm{ACR} \geq 30 \mathrm{mg} / \mathrm{g}$ & DRC & Ekulu [48] & 2019 & 40 & 12.5 \\
\hline
\end{tabular}

$H R G$, high-risk genotype; $A A$, African American; FSGS, focal segmental glomerulosclerosis; USA, United States of America; $H I V$, human immunodeficiency virus; $C K D$, chronic kidney disease; $U-A C R$, urine albumin-to-creatinine ratio; SRNS, steroid-resistant nephrotic syndrome; SSNS, steroidsensitive nephrotic syndrome; $D R C$, Democratic Republic of Congo 
African carriers not to donate without strong evidence of causality of APOL1 HRG, which would decrease the number of living donations among African American individuals [7, 8]. Thus, limiting screening to potential donors with a family history has been suggested before considering the extension of $A P O L 1$ genotyping in all donor candidates, until we have further data [8]. Consequently, a consortium, APOL1 LongTerm Kidney Transplantation Outcomes-Network (APOLLO), is conducting a prospective study on the implication of both donor and recipient $A P O L 1$ genotypes on kidney allograft outcomes. Results from APOLLO will support developing policies for matching donors with recipients to prolong allograft survival [56].

\section{Conclusions}

Besides more extensive data in adults, a few recent papers have reported the prevalence of $A P O L 1$ risk variants $\mathrm{G} 1$ and $\mathrm{G} 2$ in the general pediatric population, in children with kidney diseases, and in those at risk, especially in SCD and HIVinfected children. These data provide further evidence that carrying APOL1 HRG increases the risk for kidney disease in children of African origin. However, it has been observed that only a minority of $A P O L 1$ HRG carriers are predicted to develop $\mathrm{CKD}$, suggesting the presence of two APOL1 risk variants is necessary, but not sufficient for the development of nephropathies. A better understanding of trigger factors predisposing to APOL1 nephropathy is of great clinical importance. Moreover, questions remain about the implementation of APOL1 testing in routine clinical practice, and particularly among potential kidney donors. Plausible mechanisms whereby APOL1 risk variants promote podocyte injury have been proposed. The relevance of these cellular pathways needs to be confirmed in humans with APOL1-related nephropathies. This might allow the targeting of pathways that are more critical for organ damage in order to develop appropriate therapeutic agents.

\section{Compliance with ethical standards}

Conflict of interest The authors declare that they have no conflict of interest.

\section{References}

1. Cappuccio FP, Miller MA (2016) Cardiovascular disease and hypertension in sub-Saharan Africa: burden, risk and interventions. Intern Emerg Med 11:299-305

2. Martins D, Tareen N, Norris KC (2002) The epidemiology of endstage renal disease among African Americans. Am J Med Sci 323: $65-71$
3. Quaggin SE, George AL (2011) Apolipoprotein L1 and the genetic basis for racial disparity in chronic kidney disease. J Am Soc Nephrol 22:1955-1958

4. Moxey-Mims M (2018) Kidney disease in African American children: biological and nonbiological disparities. Am J Kidney Dis 72: S17-S21

5. Alves TP, Lewis J (2011) Racial differences in chronic kidney disease (CKD) and end-stage renal disease (ESRD) in the United States: a social and economic dilemma. Clin Nephrol 74:72-77

6. Klag MJ (1997) End-stage renal disease in African-American and white men. 16-year MRFIT findings. JAMA J Am Med Assoc 277: 1293-1298

7. Siemens TA, Riella MC, Moraes TP, Riella CV (2018) APOL1 risk variants and kidney disease: what we know so far. Brazilian J Nephrol 40:388-402

8. Reidy KJ, Hjorten R, Parekh RS (2018) Genetic risk of APOL1 and kidney disease in children and young adults of African ancestry. Curr Opin Pediatr 30:252-259

9. Freedman BI, Limou S, Ma L, Kopp JB (2018) A key contributor to racial disparities in CKD. Am J Kidney Dis 7:S8-S16

10. Kasembeli AN, Duarte R, Ramsay M, Saraladevi N (2015) African origins and chronic kidney disease susceptibility in the human immunodeficiency virus era. World J Nephrol 4:295-306

11. Kopp JB, Smith MW, Nelson GW, Johnson RC, Freedman BI, Bowden DW, Oleksyk T, McKenzie LM, Kajiyama H, Ahuja TS, Berns JS, Briggs W, Cho ME, Dart RA, Kimmel PL, Korbet SM, Michel DM, Morkrzycki MH, Schelling JR, Simon E, Trachtman H, Vlahov D, Winkler CA (2008) MYH9 is a major-effect risk gene for focal segmental glomerulosclerosis. Nat Genet 40:1175-1184

12. Kao WHL, Klag MJ, Meoni LA, Reich D, Berthier-Schaad Y, Li M, Coresh J, Patterson N, Tandon A, Powe NR, Fink NE, Sadler JH, Weir MR, Abboud HE, Adler SG, Divers J, Iyengar SK, Freedman BI, Kimmel PL, Knowler WC, Kohn OF, Kramp K, Leehey DJ, Nicholas SB, Pahl MV, Schelling JR, Sedor JR, Thornley-Brown D, Winkler CA, Smith MA, Parekh RS (2008) MYH9 is associated with nondiabetic end-stage renal disease in African Americans. Nat Genet 40:1185-1192

13. Madhavan SM, O'Toole JF (2014) The biology of APOL1 with insights into the association between APOL1 variants and chronic kidney disease. Clin Exp Nephrol 18:238-242

14. Freedman BI, Kopp JB, Langefeld CD, Genovese G, Friedman DJ, Nelson GW, Winkler CA, Bowden DW, Pollak MR (2010) The apolipoprotein L1 (APOL1) gene and nondiabetic nephropathy in African Americans. J Am Soc Nephrol 21:1422-1426

15. Genovese G, Friedman DJ, Ross MD, Lecordier L, Uzureau P, Freedman BI, Bowden DW, Langefeld CD, Oleksyk TK, Uscinski Knob A, Bernhardy AJ, Hicks PJ, Nelson GW, Vanhollebeke B, Winkler CA, Kopp JB, Pays E, Pollak MR (2010) Association of trypanolytic ApoL1 variants with kidney disease in African Americans. Science 329:841-845

16. Tzur S, Rosset S, Shemer R, Yudkovsky G, Selig S, Tarekegn A, Bekel E, Bradman N, Wasser WG, Behar DM, Shorecki K (2010) Missense mutations in the APOL1 gene are highly associated with end stage kidney disease risk previously attributed to the MYH9 gene. Hum Genet 128:345-350

17. Ray PE, Hu CAA (2011) Advances in our understanding of the pathogenesis of HIV-1 associated nephropathy in children. Futur Virol 6:883-894

18. Thomson R, Genovese G, Canon C, Kovacsics D, Higgins MK, Carrington M, Winkler CA, Kopp J, Rotimi C, Adeyemo A, Doumatey A, Ayodo G, Alper SL, Pollak MR, Friedman DJ, Raper J (2014) Evolution of the primate trypanolytic factor APOL1. Proc Natl Acad Sci U S A 111:E2130-E2139

19. Friedman DJ, Pollak MR (2016) Apolipoprotein L1 and kidney disease in African Americans. Trends Endocrinol Metab 27:204 215 
20. Pays E, Vanhollebeke B, Uzureau P, Lecordier L, Perez-Morga D (2014) The molecular arms race between African trypanosomes and humans. Nat Rev Microbiol 12:575-584

21. Vanwalleghem G, Fontaine F, Lecordier L, Tebabi P, Klewe K, Nolan DP, Yamaryo-Botté Y, Botté C, Kremer A, Burkard GS, Rassow J, Roditi I, Pérez-Morga D, Pays E (2015) Coupling of lysosomal and mitochondrial membrane permeabilization in trypanolysis by APOL. Nat Commun 6:8078

22. Limou S, Nelson GW, Kopp JB, Winkler CA (2014) APOL1 kidney risk alleles: population genetics and disease associations. Adv Chronic Kidney Dis 21:426-433

23. Lecordier L, Vanhollebeke B, Poelvoorde P, Tebabi P, PaturiauxHanocq F, Andris F, Lins L, Pays E (2009) C-Terminal mutants of apolipoprotein L-I efficiently kill both Trypanosoma brucei brucei and Trypanosoma brucei rhodesiense. PLoS Pathog 5:e1000685

24. Ma L, Divers J, Freedman BI (2019) Mechanisms of injury in APOL1 -associated kidney disease. Transplantation 103:487-492

25. Kozlitina J, Zhou H, Brown PN, Rohm RJ, Pan Y, Ayanoglu G, Du X, Rimmer E, Reilly DF, Roddy TP, Cully DF, Vogt TF, Blom D, Hoek M (2016) Plasma levels of risk-variant APOL1 do not associate with renal disease in a population-based cohort. J Am Soc Nephrol 27:3204-3219

26. Kopp JB, Nelson GW, Sampath K, Randall CJ, Genovese G, An P, Friedman D, Briggs W, Dart R, Korbet S, Mokrzycki MH, Kimmel PL, Limou S, Ahuja TS, Berns JS, Fryc J, Simon EE, Smith MC, Trachtman H, Michel DM, Schelling JR, Vlahov D, Pollak M, Winkler CA (2011) APOL1 genetic variants in focal segmental glomerulosclerosis and HIV-associated nephropathy. J Am Soc Nephrol 22:2129-2137

27. Kasembeli AN, Duarte R, Ramsay M, Mosiane P, Dickens C, DixPeek T, Limou S, Sezgin E, Nelson GW, Fogo AB, Goetsch S, Kopp JB, Winkler CA, Naicker S (2015) APOL1 risk variants are strongly associated with HIV-associated nephropathy in black South Africans. J Am Soc Nephrol 11:2882-2890

28. Divers J, Núñez M, High KP, Murea M, Rocco MV, Lijun M, Bowden DW, Hicks PJ, Spainhour M, Ornelles DA, Kleiboeker SB, Duncan K, Langefeld CD, Turner JL, Freedman BI (2013) JC polyoma virus interacts with APOL1 in African Americans with nondiabetic nephropathy. Kidney Int 84:1207-1213

29. Freedman BI, Kistler AL, Skewes-Cox P, Ganem D, Spainhour M, Turner J, Divers J, Langefeld CD, Murea M, Hicks PJ, Hemal AK, Snipes JA, Zhao L, Abend JR, Lyles DS, Ma L, Skorecki KL (2018) JC polyoma viruria associates with protection from chronic kidney disease independently from apolipoprotein L1 genotype in African Americans. Nephrol Dial Transplant 33:1960-1967

30. Nichols B, Jog P, Lee JH, Blackler D, Wilmot M, D'Agati V, Markowitz G, Kopp J, Alper SL, Pollak MR, Friedman DJ (2015) Innate immunity pathways regulate the nephropathy gene apolipoprotein L1. Kidney Int 87:332-342

31. Obermoser G, Pascual V (2010) The interferon- $\alpha$ signature of systemic lupus erythematosus. Lupus 19:1012-1019

32. Hayek SS, Koh KH, Grams ME, Wei C, Ko YA, Li J, Samelko B, Dande RR, Lee HW, Hahm E, Peev V, Tracy M, Tardi NJ, Gupta V, Altintas MM, Garborcauskas G, Stojanocic N, Winkler CA, Lipkowitz MS, Tin A, Inker LA, Levey AS, Zeier M, Freedman BI, Kopp JB, Skorecki K, Coresh J, Quyyumi AA, Sever S, Reiser J (2017) A tripartite complex of suPAR, APOL1 risk variants and $\alpha \mathrm{v}$ $\beta 3$ integrin on podocytes mediates chronic kidney disease. Nat Med 23:945-956

33. Langefeld CD, Comeau ME, Ng MCY, Guan M, Dimitrov L, Mudgal P, Spainhour MH, Julian BA, Edberg JC, Croker JA, Divers J, Hicks PJ, Bowden DW, Chan GC, Ma L, Palmer ND, Kimberly RP, Freedman BI (2018) Genome-wide association studies suggest that APOL1-environment interactions more likely trigger kidney disease in African Americans with nondiabetic nephropathy than strong APOL1-second gene interactions. Kidney Int 94:599-607

34. Heymann J, Winkler CA, Hoek M, Susztak K, Kopp JB (2017) Therapeutics for APOL1 nephropathies: putting out the fire in the podocyte. Nephrol Dial Transplant 32:i65-i70

35. Uzureau S, Coquerelle C, Vermeiren C, Uzureau P, Van Acker A, Pilotte L, Monteyne D, Acolty V, Vanhollebeke B, Van den Eynde B, Pérez-Morga D, Moser M, Pays E (2016) Apolipoproteins L control cell death triggered by TLR3/TRIF signaling in dendritic cells. Eur J Immunol 46:1854-1866

36. Okamoto K, Rausch JW, Wakashin H, Fu Y, Chung JY, Dummer PD, Shin MK, Chandra P, Suzuki K, Shrivastav S, Rosenberg AZ, Hewitt SM, Ray PE, Noiri E, Le Grice SFJ, Hoek M, Han Z, Winkler CA, Kopp JB (2018) APOL1 risk allele RNA contributes to renal toxicity by activating protein kinase R. Commun Biol 1:188

37. Ma L, Snipes JA, Murea M, Freedman BI, Chou JW, Hawkins GA, Langefeld CD, Bharadwaj MS, Molina AJ, Craddock AL, Miller LD, Cheng D, Weckerle A, Parks JS, Petrovic S, Hicks PJ, Hemal AK (2017) APOL1 renal-risk variants induce mitochondrial dysfunction. J Am Soc Nephrol 28:1093-1105

38. Olabisi OA, Zhang J-Y, VerPlank L, Zahler N, DiBartolo S, Heneghan JF, Schlöndorff JS, Hee Suh J, Yan P, Alper SL, Friedman DJ, Pollak MR (2016) APOL1 kidney disease risk variants cause cytotoxicity by depleting cellular potassium and inducing stress-activated protein kinases. Proc Natl Acad Sci U S A 113: $830-837$

39. Lan X, Jhaveri A, Cheng K, Wen H, Saleem MA, Mathieson PW, Mikulak J, Aviram S, Malhotra A, Skorecki K, Singhal PC (2014) APOL1 risk variants enhance podocyte necrosis through compromising lysosomal membrane permeability. Am J Physiol Physiol 307:F326-F336

40. Beckerman P, Bi-Karchin J, Park ASD, Qiu C, Dummer PD, Soomro I, Boustany-Kari CM, Pullen SS, Miner JH, Hu CAA, Rohacs T, Inoue K, Ishibe S, Saleem MA, Palmer MB, Cuervo AM, Kopp JB, Susztak K (2017) Transgenic expression of human APOL1 risk variants in podocytes induces kidney disease in mice. Nat Med 23:429-438

41. Kumar V, Paliwal N, Ayasolla K, Vashistha H, Jha A, Chandel N, Chowdhary S, Saleem MA, Malhotra A, Chander PN, Skorecki K, Singhal PC (2019) Disruption of APOL1-miR193a axis induces disorganization of podocyte actin cytoskeleton. Sci Rep 9:3582

42. Adeyemo A, Esezobor C, Solarin A, Abeyagunawardena A, Kari JA, El Desoky S, Greenbaum LA, Kamel M, Kallash M, Silva C, Young A, Hunley TE, de Jesus-Gonzalez N, Srivastava T, Gdadegesin R (2018) HLA-DQA1 and APOL1 as risk loci for childhood-onset steroid-sensitive and steroid-resistant nephrotic syndrome. Am J Kidney Dis 71:399-406

43. Freedman BI, Skorecki K (2014) Gene-gene and geneenvironment interactions in apolipoprotein L1 gene-associated nephropathy. Clin J Am Soc Nephrol 9:2006-2013

44. Hoy WE, Hughson MD, Kopp JB, Mott SA, Bertram JF, Winkler CA (2015) APOL1 risk alleles are associated with exaggerated agerelated changes in glomerular number and volume in AfricanAmerican adults: an autopsy study. J Am Soc Nephrol 26:31793189

45. Freedman BI, Langefeld CD, Lu L, Palmer ND, Smith SC, Bagwell BM, Hicks PJ, Xu J, Wagenknecht LE, Raffield LM, Register TC, Carr JJ, Bowden DW, Divers J (2015) APOL1 associations with nephropathy, atherosclerosis, and all-cause mortality in African Americans with type 2 diabetes. Kidney Int 87:176-181

46. Ng DK, Robertson CC, Woroniecki RP, Limou S, Gillies CE, Reidy KJ, Winkler CA, Hingorani S, Gibson KL, Hjorten R, Cb S, Kopp JB, Moxey-Mims M, Furth SL, Warady BA, Kretzler M, Sedor JR, Kaskel FJ, Sampson MG (2017) APOL1-associated glomerular disease among African-American children: a collaboration of the Chronic Kidney Disease in Children (CKiD) and Nephrotic 
Syndrome Study Network (NEPTUNE) cohorts. Nephrol Dial Transplant 32:983-990

47. Purswani MU, Patel K, Winkler CA, Spector SA, Hazra R, Seage GR, Mofenson L, Karalius B, Scott GB, Van Dyke RB, Kopp JB (2016) Brief report: APOL1 renal risk variants are associated with chronic kidney disease in children and youth with perinatal HIV infection. J Acquir Immune Defic Syndr 73:63-68

48. Ekulu PM, Nkoy AB, Betukumesu DK, Aloni MN, Makulo JR, Sumaili EK, Mafuta EM, Elmonem MA, Arcolino FO, Kitetele FN, Lepira FB, Van den Heuvel LP, Levtchenko EN (2019) APOL1 risk genotypes are associated with early kidney damage in children in Sub-Saharan Africa. Kidney Int Rep 4:930-938

49. Kormann R, Jannot AS, Narjoz C, Ribeil JA, Manceau S, Delville M, Joste V, Prié D, Pouchot J, Thervet E, Courbebaisse M, Arlet JB (2017) Roles of APOL1 G1 and G2 variants in sickle cell disease patients: kidney is the main target. Br J Haematol 179:323-335

50. Geard A, Pule GD, Chemegni BC, Ngo Bitoungui VJ, Kengne AP, Chimusa ER, Wonkam A (2017) Clinical and genetic predictors of renal dysfunctions in sickle cell anaemia in Cameroon HHS public access. Br J Haematol 178:629-639

51. Watanabe A, Feltran LS, Sampson MG (2019) Genetics of nephrotic syndrome presenting in childhood: core curriculum. Am J Kidney Dis 74:549-557

52. Woroniecki RP, Ng DK, Limou S, Winkler CA, Reidy KJ, Mitsnefes M, Sampson MG, Wong CS, Warady BA, Furth SL, Kopp JB, Kaskel KJ (2016) Renal and cardiovascular morbidities associated with APOL1 status among African-American and nonAfrican-American children with focal segmental glomerulosclerosis. Front Pediatr 4:426-433

53. Guan I, Singer P, Frank R, Chorny N, Infante L, Sethna CB (2016) Role of race in kidney transplant outcomes in children with focal segmental glomerulosclerosis. Pediatr Transplant 20:790-797

54. Freedman BI, Pastan SO, Israni AK, Schladt D, Julian BA, Gautreaux MD, Hauptfeld V, Bray RA, Gebel HM, Kirk AD, Gaston RS, Rogers J, Farney AC, Orlando G, Stratta RJ, Mohan S, Ma L, Langefeld CD, Bowden DW, Hicks PJ, PAlmer ND, Palanisamy A, Reeves-Daniel AM, Brown WM, Divers J (2016) APOL1 genotype and kidney transplantation outcomes from deceased African American donors. Transplantation 100:194-202

55. Lee BT, Kumar V, Williams TA, Bernhardy A, Dyer C, Conte S, Gnovese G, Ross MD, Friedman DJ, Gaston R, Milford E, Pollak MR, Chandraker A (2012) The APOL1 genotype of African American kidney transplant recipients does not impact 5-year allograft survival. Am J Transplant 12:1924-1928

56. Freedman BI, Moxey-Mims M (2018) The APOL1 long-term kidney transplantation outcomes network-APOLLO. Clin J Am Soc Nephrol 13:940-942

Publisher's note Springer Nature remains neutral with regard to jurisdictional claims in published maps and institutional affiliations. 